\title{
A Predictive Risk Model for Electroshock-Induced Mortality of the Endangered Cape Fear Shiner
}

\author{
F. Michael Holliman* and James B. Reynolds \\ Alaska Cooperative Fish and Wildlife Research Unit ${ }^{1}$ \\ and School of Fisheries and Ocean Sciences, University of Alaska-Fairbanks, \\ Post Office Box 757020, Fairbanks, Alaska 99775-7020, USA
}

\section{THOMAS J. KWAK}

\begin{abstract}
U.S. Geological Survey, North Carolina Cooperative Fish and Wildlife Research Unit, ${ }^{2}$ Campus Box 7617, North Carolina State University, Raleigh, North Carolina 27695-7617, USA
\end{abstract}

\begin{abstract}
We evaluated the effects of a single electroshock on injury and mortality of hatcheryreared Cape Fear shiners Notropis mekistocholas $(N=517)$, an endangered cyprinid. Groups of 18-22 Cape Fear shiners were exposed to DC, 120-Hz pulsed DC (PDC), or 60-Hz PDC at voltage gradients of $1.1,1.9$, or $2.7 \mathrm{~V} / \mathrm{cm}$ for $3 \mathrm{~s}$. Mortality occurred only among fish exposed to $120-\mathrm{Hz}$ PDC (25\%) and DC (38\%) applied at $2.7 \mathrm{~V} / \mathrm{cm}$. Because no mortality occurred in Cape Fear shiners exposed to $60-\mathrm{Hz}$ PDC, this waveform was selected for further study of electroshock duration $(3,6,12,24$, or $48 \mathrm{~s})$ and voltage gradient $(0.9,1.6$, or $2.3 \mathrm{~V} / \mathrm{cm})$. Most fish electroshocked in the experiments were immobilized (ceased swimming motion). No physical injury was detected by necropsy or radiography in any fish. Electroshock-induced mortality of Cape Fear shiners showed a strong multivariable relationship to voltage gradient, electroshock duration, and fish length. Fish subjected to $60-\mathrm{Hz}$ PDC at 0.9 or $1.6 \mathrm{~V} / \mathrm{cm}$ for $6 \mathrm{~s}$ experienced low mortality $(<10 \%)$. Our results demonstrate that Cape Fear shiners can be immobilized by 60-Hz PDC electroshock without injury or significant risk of mortality. We propose that electrofishing may be safely used to sample similar small cyprinids, imperiled or otherwise, when electrofishers select an appropriate waveform (DC pulsed at $60-\mathrm{Hz}$ or less) and use it judiciously (minimal exposure at, or below, the immobilization threshold).
\end{abstract}

The United States harbors the most diverse temperate fish fauna in the world, and the greatest concentration of these species occurs in the Southeast (Warren and Burr 1994). However, that rich fauna is imperiled and declining (Warren et al. 2000). The U.S. Fish and Wildlife Service is charged with monitoring and developing recovery plans that include objective, measurable population criteria, based on scientific sampling, for each threatened and endangered species under the U.S. Endangered Species Act of 1973. Electrofishing is a viable and efficient sampling technique for many freshwater species (Reynolds 1996); however, its use for sampling threatened or endangered fishes has been discouraged or prohibited by some re-

\footnotetext{
* Corresponding author: fffmh@uaf.edu

${ }^{1}$ The Unit is sponsored by the Alaska Department of Fish and Game, U.S. Geological Survey, U.S. Fish and Wildlife Service, University of Alaska-Fairbanks, and Wildlife Management Institute.

2 The Unit is sponsored by North Carolina State University, North Carolina Wildlife Resources Commission, U.S. Geological Survey, and Wildlife Management Institute.
}

Received January 20, 2002; accepted January 8, 2003 source agencies to avoid the risk of fish injury or mortality. Because harm to individuals in small, threatened populations could translate into population effects (Nielsen 1998), the consequences of scientific sampling should be evaluated.

The Cape Fear shiner Notropis mekistocholas is a small (adults range from 45 to $60 \mathrm{~mm}$ standard length in the wild), endangered cyprinid endemic to the Cape Fear drainage of North Carolina (Snelson 1971; USFWS 1988). A need for population, habitat, and life history information for this cyprinid raised the issue of the use of electrofishing and possible harm to fish. Based on prior studies on small fish, we identified electrical waveform, pulse frequency, voltage gradient, electroshock duration, and fish length as potential risk factors for mortality of electroshocked Cape Fear shiners. Whether these variables influence injury in small fish is not known, but injury to Cape Fear shiners was a concern because electroshock-induced injury has been reported in fish about 40-100 mm long (Ruppert and Muth 1997; Cooke et al. 1998).

Considerable effort has been expended to understand and reduce the lethal and sublethal effects of electroshock on fish, the most recent studies 
evaluating electroshock-induced injury in adult salmonids. How factors such as electrical waveform, voltage gradient, electroshock duration, and fish length affect injury and mortality in small fish is largely unknown. The ability to predict which factors have the greatest influence on fish injury and mortality would be a very useful selection tool for biologists, whether applied to healthy populations or rare and threatened fish. Prognostic models are powerful tools frequently used in studies of clinical outcomes. Critical application of modeling techniques is needed to ensure that these models fit the dataset at hand, without being overfitted, and are accurate predictors of outcome (Harrell et al. 1996).

The purpose of this study was to determine whether multivariables, specifically electrical waveform, voltage gradient, exposure duration, and fish length, are related to injury and mortality of Cape Fear shiners after electroshock. We first determined the least damaging electrical waveform and then evaluated the effects of various voltage gradients and exposure periods. For inference and simulation purposes, we then developed a prognostic model for relating voltage gradient, electroshock duration, and fish length to Cape Fear shiner mortality.

\section{Methods}

Groups of hatchery-reared Cape Fear shiners were subjected to electroshock in tank experiments to evaluate injury and mortality. Two experiments were performed: (1) at Edenton National Fish Hatchery, U.S. Fish and Wildlife Service, Edenton, North Carolina, on 13-15 October 1999, and (2) at the North Carolina Cooperative Fish and Wildlife Research Unit, North Carolina State University, Raleigh, on 7-10 October 2000. The fish were reared from Deep River and Rocky River broodstock and provided by the Edenton hatchery. Similarity in fish length distributions for the two experiments was compared using a two-sided $t$ test (SAS 1999).

Equipment.-All tests were conducted in a rectangular fiberglass tank measuring $168 \mathrm{~cm} \times 42$ $\mathrm{cm}$ that was filled with water to a depth of $13 \mathrm{~cm}$. Two parallel electrodes (flat steel plates) set 125 $\mathrm{cm}$ apart covered the cross-sectional area of the tank, producing a linear change in voltage (i.e., a constant voltage gradient) along the length of the tank. Two Smith-Root (Vancouver, Washington) backpack electrofishing control units were used as power supplies for the test tank. In the 1999 experiment, the backpack unit was modified to allow fine adjustment of the output voltage and programmed to ensure each treatment was applied for $3 \mathrm{~s}$. Electrical energy was supplied to this unit from a $120-\mathrm{V}$ electrical outlet. An unmodified backpack unit powered by a fully charged gel cell battery was used in the 2000 experiment, wherein treatment duration (s) was measured with an external timer. A calibrated, digital oscilloscope was used to confirm the waveform and potential difference applied across the electrodes during all treatments. No difference was discernible in the electrical waveforms generated by the two units, with respect to pulse frequency, pulse width, or pulse shape.

Water conductivity in the test tank was adjusted by deionization to levels normally associated with the habitat of Cape Fear shiners (J. Bales, U.S. Geological Survey, unpublished data). Ambient conductivity was $224 \mu \mathrm{S} / \mathrm{cm}$ at $21^{\circ} \mathrm{C}$ in the 1999 experiment and $228-238 \mu \mathrm{S} / \mathrm{cm}$ at $21-22^{\circ} \mathrm{C}$ in the 2000 experiment.

Experimental procedures.-Naive Cape Fear shiners were subjected to treatments in experimental groups of 18-22 fish. Individual fish were assigned to groups, which were then randomly assigned to experimental treatments, including control designation. Control groups were subjected to the same procedures as the treatment groups, except for exposure to an electric field.

Treatments differed between the two experiments. To evaluate the effects of electric waveform and field intensity in the 1999 experiment, minnows were exposed $(3 \mathrm{~s})$ to $1.1,1.9$, or $2.7 \mathrm{~V} / \mathrm{cm}$ peak voltage gradients $(140,240$, and $340 \mathrm{~V})$ using continuous DC, $60-\mathrm{Hz}$ PDC, or $120-\mathrm{Hz}$ PDC. The two PDC waveforms were pulsed square waves with 4-ms pulse duration, resulting in $24 \%$ (60$\mathrm{Hz})$ or $48 \%(120-\mathrm{Hz})$ duty cycles. In the 2000 experiment we used only $60-\mathrm{Hz}$ PDC and evaluated the effects of electroshock duration and voltage gradient. Fish were exposed to peak voltage gradients of $0.9,1.6$, or $2.3 \mathrm{~V} / \mathrm{cm}(100,200$, or $300 \mathrm{~V}$ ) for $3,6,12,24$, or $48 \mathrm{~s}$. The order of treatment application was randomized within each experiment.

A total of 203 Cape Fear shiners were used in the 1999 experiment and 314 in the 2000 study. In the 1999 experiment, the groups of fish were confined in plastic-mesh cages $(35 \times 20 \times 24 \mathrm{~cm})$ during and after treatment. In the 2000 experiment, the groups of fish were confined in a nylon-mesh dip net during treatment and transferred to plastic mesh holding pens afterward. In-water voltage measurements confirmed that the electric field was 
not influenced by the cages or dip net used to hold the fish during treatment.

Fish response is dependent upon in vivo electrical energy (Kolz 1989); thus, the response of individual fish within an experimental group was independent of that of other fish in the group. We simulated fish response and survival in various electrofishing fields by exposing groups to different electrical waveforms, voltage gradients, and periods of time. Because electrofishing fields are greatly diminished as distance from the anode increases, fish response and survival in our study simulated the most severe response and worst-case survival outcome for electrofishing at a given voltage (hence, voltage gradient) level.

The predominant behavioral response evoked in each experimental group during treatment was categorized using a scheme based on the recommendations of Sternin et al. (1976) for occasions when a detailed classification of fish response is not required. The response categories are useful for and observable while electrofishing: escape (strong swimming not directed to the electrodes); forced swimming, either taxis (strong, oriented swimming to the anode) or psuedoforced swimming (unbalanced swimming to the anode); and immobilization (complete cessation of swimming motion). Immobilization was considered the most severe electroshock and escape the least severe.

The experimental groups, including control groups, were held for $36 \mathrm{~h}$ after treatment and observed periodically to determine mortality. Water temperatures in the holding facilities were $21-$ $22^{\circ} \mathrm{C}$ during the posttreatment observation period. No rations were provided to the experimental fish during this time. Dead fish were removed at 4, 6 , or $12 \mathrm{~h}$ posttreatment. The surviving fish were subjected to a lethal dose of MS-222 (tricaine methanesulfonate) at the conclusion of the observation period.

Both dead and surviving fish were measured for total length $(\mathrm{mm})$ and weight $(\mathrm{g})$ and examined for electroshock-induced injuries (broken blood vessels and vertebral damage) via radiography and necropsy. Dorsoanterior and lateral projection radiographs were taken. Despite the use of mammography film and screens, the small size of these fish compromised the usefulness of radiography for identifying injury to individual vertebrae. Injury assessment relied primarily on necropsy. During necropsy, fillets were removed from the fish bilaterally with surgical scalpels. The vertebral column and fillets were examined via microscopy under transmitted and reflected light. Hemorrhage and vertebral injury were reported separately as present or absent.

Model selection and inference.-Outcome variables of interest were the electroshock-induced injury and mortality of individual fish, which were treated as binary data sets. Counts, proportions, and percentages were employed to summarize relationships between independent variables (waveform and voltage gradient in the 1999 experiment; voltage gradient and period of exposure in the 2000 experiment) and the outcome variables. In the 1999 experiment, treatment effects were evaluated using Fisher's exact test (SAS 1999) to determine which waveform to use in the 2000 experiment. In the 2000 experiment, voltage gradient $(E)$, electroshock duration $(T)$, and fish total length $(L)$ were treated as candidate predictors of Cape Fear shiner mortality. Logistic regression (SAS 1999), via a differential-effects model, was employed to evaluate univariate models $(E ; T$; and $L)$ and multivariable models $(E, T ; E, L ; T, L$; and $E$, $T, L)$. Voltage gradient and electroshock duration were treated as categorical variables, whereas fish length was treated as a continuous variable in the models.

Akaike's information criterion (AIC) is an approximation of the information lost in the conversion from data to model that includes a penalty for number of model parameters. Smaller AIC values indicate smaller losses of information, which can be used to objectively evaluate alternative models (Buckland et al. 1997; Thompson et al. 1997; Burnham and Anderson 1998; Franklin et al. 2001). A single, best prognostic model for electroshock-induced mortality was selected from the candidate set using the differences in AIC values between each model and the model with the smallest AIC value $\left(\Delta_{i}=\mathrm{AIC}_{i}-\min [\mathrm{AIC}]\right)$. The larger the $\Delta_{i}$, the less plausible the fitted model is to be the best; models with $\Delta_{i}$ greater than 10 fail to explain substantial variation in the data (Burnham and Anderson 1998). Normalized Aikaike weights were calculated for each model in the candidate set of $R$ models, using $w_{i}=\exp \left(-\Delta_{i} / 2\right) /$ $\sum_{r=1}^{R} \exp \left(-\Delta_{r} / 2\right)$ to allow comparison of model probabilities or plausibility (Burnham and Anderson 1998; Franklin et al. 2001). Model calibration was evaluated using the Hosmer and Lemeshow goodness-of-fit test (GOF; SAS 1999; Hosmer and Lemeshow 2000). The area under the receiveroperating characteristic curve (ROC), a measure of the instrument's overall predictive capability (defined in this study as the ability to separate those fish likely to die from those likely to sur- 
TABLE 1.-Percentages of incapacitated and dead (parentheses) Cape Fear shiners in the 1999 experiment, according to electrical treatment and time after treatment. Treatment group size ranged from 18 to 22 fish; PDC stands for pulsed DC.

\begin{tabular}{ccccc}
\hline & \multicolumn{4}{c}{ Treatment group } \\
\cline { 2 - 5 } Time after & $2.7 \mathrm{~V} / \mathrm{cm}$ & $\begin{array}{c}2.7 \mathrm{~V} / \mathrm{cm}, \\
120-\mathrm{Hz}\end{array}$ & $\begin{array}{c}2.7 \mathrm{~V} / \mathrm{cm}, \\
60-\mathrm{Hz}\end{array}$ & $\begin{array}{c}\text { All } \\
\text { PDC }\end{array}$ \\
others \\
\hline 0.33 & $14(0)$ & $35(0)$ & $5(0)$ & $0(0)$ \\
0.67 & $14(0)$ & $35(0)$ & $5(0)$ & $0(0)$ \\
1.00 & $43(5)$ & $35(0)$ & $0(0)$ & $0(0)$ \\
1.33 & $43(10)$ & $25(5)$ & $0(0)$ & $0(0)$ \\
1.67 & $29(19)$ & $25(5)$ & $0(0)$ & $0(0)$ \\
12.00 & $0(38)$ & $0(25)$ & $0(0)$ & $0(0)$ \\
36.00 & $0(38)$ & $0(25)$ & $0(0)$ & $0(0)$ \\
\hline
\end{tabular}

vive), was used to evaluate model discrimination. Models with ROC areas above 0.80 have been endorsed for individual predictions (Johnston et al. 2000). Null hypotheses regarding the effects of individual levels of voltage gradient and exposure period were evaluated using Wald chi-square tests (SAS 1999) in the model determined to best represent the empirical data.

\section{Results}

Cape Fear shiners in the 1999 experiment were $43-82 \mathrm{~mm}$ in total length (mean $\pm \mathrm{SD}=62 \pm 10$ $\mathrm{mm}$ ), and those in the 2000 experiment were 25 $65 \mathrm{~mm}(43 \pm 7 \mathrm{~mm})$. Fish length distributions varied significantly between the two experiments $(t=24$, df $=332, P=0.0001)$.

In the 1999 experiment, no injury was detected in any of the fish and mortality depended upon both voltage gradient and waveform. Immobilization was elicited in seven of the nine electrical treatment groups; exceptions were the escape response elicited in the $1.1-\mathrm{V} / \mathrm{cm}$ DC group and a well-defined taxis response in the $1.9-\mathrm{V} / \mathrm{cm}$ DC group. Although there was no immediate mortality, several individuals were moribund (i.e., remained incapacitated $1 \mathrm{~h}$ after treatment) in groups subjected to DC (43\%) and $120-\mathrm{Hz}$ PDC (35\%) at $2.7 \mathrm{~V} / \mathrm{cm}$. Only $5 \%$ of the minnows in the $2.7 \mathrm{~V} /$ $\mathrm{cm}, 60-\mathrm{Hz}$ PDC group were incapacitated posttreatment (Table 1). No mortality occurred in the control group or in seven of the nine experimental groups; exceptions were in the $2.7-\mathrm{V} / \mathrm{cm}$ DC $(38 \%$ mortality) group and the $2.7-\mathrm{V} / \mathrm{cm}, 120-\mathrm{Hz}$ PDC (25\% mortality) group. Total mortality did not differ significantly between the DC and $120-\mathrm{Hz}$ treatment groups, as indicated by Fisher's exact test $(P$ $=0.31$ ). All deaths in the experiment occurred within $12 \mathrm{~h}$ after treatment (Table 1). Necropsy
TABLE 2.-Counts of Cape Fear shiners incapacitated or dead at $0.33,0.67$, and $1.00 \mathrm{~h}$ and dead at $36 \mathrm{~h}$, along with the proportion dead in the treatment group at $36 \mathrm{~h}$ after treatment in the 2000 experiment. Treatment group size ranged from 18 to 22 fish.

\begin{tabular}{|c|c|c|c|c|c|}
\hline \multirow{2}{*}{$\begin{array}{l}\text { Exposure } \\
\text { period }(\mathrm{s})\end{array}$} & \multicolumn{3}{|c|}{ Incapacitated or dead at } & \multirow{2}{*}{$\begin{array}{l}\text { Dead } \\
\text { at } \\
36 \mathrm{~h}\end{array}$} & \multirow{2}{*}{$\begin{array}{c}\text { Proportion } \\
\text { dead } \\
\text { at } 36 \mathrm{~h}\end{array}$} \\
\hline & $0.33 \mathrm{~h}$ & $0.67 \mathrm{~h}$ & $1.00 \mathrm{~h}$ & & \\
\hline \multicolumn{6}{|c|}{ Voltage gradient $=0.9 \mathrm{~V} / \mathrm{cm}$} \\
\hline 3 & 0 & 0 & 0 & 0 & 0.00 \\
\hline 6 & 0 & 0 & 0 & 0 & 0.00 \\
\hline 12 & 2 & 1 & 1 & 1 & 0.05 \\
\hline 24 & 1 & 0 & 1 & 1 & 0.05 \\
\hline 48 & 1 & 1 & 1 & 1 & 0.05 \\
\hline \multicolumn{6}{|c|}{ Voltage gradient $=1.6 \mathrm{~V} / \mathrm{cm}$} \\
\hline 3 & 0 & 0 & 0 & 0 & 0.00 \\
\hline 6 & 1 & 0 & 0 & 0 & 0.00 \\
\hline 12 & 1 & 1 & 1 & 1 & 0.05 \\
\hline 24 & 10 & 8 & 7 & 8 & 0.42 \\
\hline 48 & 14 & 14 & 13 & 4 & 0.74 \\
\hline \multicolumn{6}{|c|}{ Voltage gradient $=2.3 \mathrm{~V} / \mathrm{cm}$} \\
\hline 3 & 0 & 0 & 0 & 0 & 0.00 \\
\hline 6 & 1 & 1 & 1 & 1 & 0.05 \\
\hline 12 & 8 & 5 & 5 & 5 & 0.26 \\
\hline 24 & 16 & 16 & 15 & 15 & 0.79 \\
\hline 48 & 17 & 14 & 14 & 14 & 0.70 \\
\hline
\end{tabular}

revealed no evidence of electroshock-induced injury (i.e., broken blood vessels or vertebral damage) in dead or surviving Cape Fear shiners. Because no fish died after exposure to $60-\mathrm{Hz}$ PDC, this waveform was selected for further evaluation in the 2000 experiment.

During the 2000 experiment, immobilization, intermittently interrupted by movement, was evoked in the groups exposed to $0.9 \mathrm{~V} / \mathrm{cm}$, whereas instantaneous immobilization was evoked in the groups exposed to 1.6 and $2.3 \mathrm{~V} / \mathrm{cm}$. Necropsy revealed no evidence for electroshock-induced injury in any of the experimental animals. Of the 61 Cape Fear shiners that died, 2\% (1) had been electroshocked using $60-\mathrm{Hz}$ PDC for $6 \mathrm{~s}, 11 \%$ (7) for $12 \mathrm{~s}, 39 \%$ (24) for $24 \mathrm{~s}$, and $48 \%$ (29) for $48 \mathrm{~s}$ (Table 2). Mortality was higher in the treatment groups exposed to $2.3 \mathrm{~V} / \mathrm{cm}(57 \%)$ or $1.6 \mathrm{~V} / \mathrm{cm}$ (38\%) than in groups exposed to $0.9 \mathrm{~V} / \mathrm{cm}(5 \%)$. No mortality occurred in the control group or groups subjected to $60-\mathrm{Hz}$ PDC for $3 \mathrm{~s}$, regardless of voltage gradient.

Logistic regression demonstrated a multivariable relationship between voltage gradient $(E)$, exposure duration ( $T$ ), fish length $(L)$, and electroshockinduced mortality outcome. Because the lack of mortality in the 3-s treatment groups resulted in a quasi-complete separation (near division of the data caused by zero cells that results in poor pa- 
TABLE 3.-Differences in Akaike information criterion (AIC) values $\left(\Delta_{i}\right)$, normalized Akaike weights $\left(w_{i}\right)$, goodness of fit (GOF) and the area under the receiver operating characteristic (ROC) curve for prognostic models of electroshock-induced mortality of Cape Fear shiners, where $E$ $=$ voltage gradient, $T=$ exposure duration, and $L=$ total length.

\begin{tabular}{clrccc}
\hline Rank & $\begin{array}{c}\text { Candidate } \\
\text { models }\end{array}$ & \multicolumn{1}{c}{$\Delta_{i}$} & $w_{i}$ & $\begin{array}{c}\text { GOF } \\
(P \text {-value })\end{array}$ & $\begin{array}{c}\text { Area under } \\
\text { ROC curve }\end{array}$ \\
\hline 1 & $E, T, L$ & 0 & 1.00 & 0.92 & 0.94 \\
2 & $E, T$ & 37 & 0.00 & 0.45 & 0.90 \\
3 & $T, L$ & 69 & 0.00 & 0.28 & 0.84 \\
4 & $T$ & 84 & 0.00 & 1.00 & 0.78 \\
5 & $E, L$ & 86 & 0.00 & 0.72 & 0.80 \\
6 & $E$ & 97 & 0.00 & 1.00 & 0.74 \\
7 & $L$ & 130 & 0.00 & 0.88 & 0.60 \\
\hline
\end{tabular}

rameter estimation), we excluded the 3 -s treatment data. Goodness-of-fit tests for each model tested supported the hypothesis that the model fit the data $\left(\chi^{2}=0.0000-9.9237\right.$, df $=1-10, P=0.2819-$ 1.0000). Model discrimination, as indicated by the area under the ROC curve, ranged from poor (0.60) for $L$ to outstanding (0.94) for the $E, T, L$ model (Table 3 ). The $E$ model, $T$ model, and $L$ model demonstrated that each of these factors were significant single predictors of mortality of Cape Fear shiners subjected to $60-\mathrm{Hz}$ PDC. Similarly, the $E$, $T$ model and $T, L$ model fit the data and each had very good discriminatory abilities, but failed to explain the variations in the data as well as the $E$, $T$, $L$ model, as indicated by $\Delta_{i}$ (Table 3 ). Further, the Akaike weights presented very strong evidence for the $E, T, L$ model being the best model. Hence, the $E, T, L$ model was selected as the best of the candidate set and had an area under the ROC curve of 0.94 .

Field intensity $\left(\chi^{2}=32.7\right.$, df $\left.=2, P<0.0001\right)$, exposure period $\left(\chi^{2}=35.9\right.$, df $\left.=3, P<0.0001\right)$, and fish length $\left(\chi^{2}=23.4\right.$, df $\left.=1, P<0.0001\right)$ were significantly related to the probability of mortality $(P=0.0001)$ in the $E, T, L$ model. Individual differences in voltage gradient effects were demonstrated by hypothesis tests, specifically, $H_{0}: 0.9$ $\mathrm{V} / \mathrm{cm}=1.6\left(\chi^{2}=19.4\right.$, df $\left.=1, P<0.0001\right), H_{0}$ : $0.9 \mathrm{~V} / \mathrm{cm}=2.7 \mathrm{~V} / \mathrm{cm}\left(\chi^{2}=32.6\right.$, df $=1, P<$ $0.0001)$, and $H_{0}: 1.6 \mathrm{~V} / \mathrm{cm}=2.7 \mathrm{~V} / \mathrm{cm}\left(\chi^{2}=11.9\right.$, df $=1, P=0.0006)$. Hypothesis tests to determine whether the differential effects were equal in the periods of exposure indicated a threshold was reached between 24 and $48 \mathrm{~s}$, specifically, $H_{0}: 6 \mathrm{~s}=$ $12 \mathrm{~s}\left(\chi^{2}=7.5, \mathrm{df}=1, P=0.0075\right), H_{0}: 6 \mathrm{~s}=$ $24 \mathrm{~s}\left(\chi^{2}=21.8\right.$, df $\left.=1, P<0.0001\right), H_{0}: 6 \mathrm{~s}=$ $48 \mathrm{~s}\left(\chi^{2}=26.5\right.$, df $\left.=1, P<0.0001\right), H_{0}: 12 \mathrm{~s}=$ $24 \mathrm{~s}\left(\chi^{2}=17.5\right.$, df $\left.=1, P<0.0001\right), H_{0}: 12 \mathrm{~s}=$
TABLE 4.-Estimated coefficients, 95\% confidence intervals (CIs), and standard errors of the $E, T, L$ model, which was the best prognostic model of electroshockinduced mortality of Cape Fear shiners exposed to $60-\mathrm{Hz}$ PDC.

\begin{tabular}{|c|c|c|c|}
\hline Characteristic & $\begin{array}{l}\text { Estimated } \\
\text { coefficient }\end{array}$ & $95 \% \mathrm{CI}$ & SE \\
\hline Intercept & -13.96 & & 2.60 \\
\hline \multicolumn{4}{|c|}{ Voltage gradient $(E)$} \\
\hline $0.9 \mathrm{~V} / \mathrm{cm}$ & -3.11 & -4.25 to -1.98 & 0.58 \\
\hline $1.6 \mathrm{~V} / \mathrm{cm}$ & 0.57 & -0.10 to 1.25 & 0.34 \\
\hline $2.3 \mathrm{~V} / \mathrm{cm}$ & 2.54 & 1.64 to 3.44 & 0.46 \\
\hline \multicolumn{4}{|c|}{ Electroshock duration $(T)$} \\
\hline $6 \mathrm{~s}$ & -4.26 & -6.15 to -2.37 & 0.96 \\
\hline $12 \mathrm{~s}$ & -0.94 & -1.91 to 0.03 & 0.49 \\
\hline $24 \mathrm{~s}$ & 2.13 & 1.16 to 3.10 & 0.49 \\
\hline $48 \mathrm{~s}$ & 3.07 & 1.99 to 4.16 & 0.55 \\
\hline \multicolumn{4}{|l|}{ Length $(L)$} \\
\hline $25-66 \mathrm{~mm}$ & 0.25 & 0.15 to 0.35 & 0.05 \\
\hline
\end{tabular}

$48 \mathrm{~s}\left(\chi^{2}=26.2\right.$, df $\left.=1, P<0.0001\right)$, and $H_{0}: 24$ $\mathrm{s}=48 \mathrm{~s}\left(\chi^{2}=3.1\right.$, df $\left.=1, P=0.0806\right)$.

The predicted probability of mortality was minimal in 25-65-mm Cape Fear shiners subjected to $60-\mathrm{Hz} \mathrm{PDC}$ at 0.9 or $1.6 \mathrm{~V} / \mathrm{cm}$ for $6 \mathrm{~s}$ (Table 4; Figure 1). When electroshock duration was $6 \mathrm{~s}$,

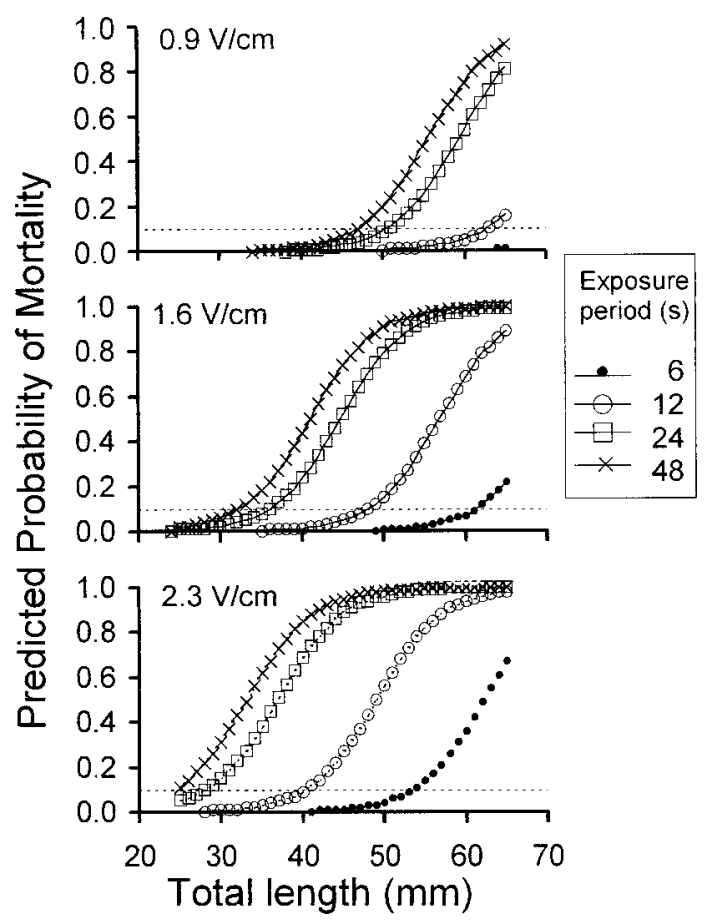

FIGURE 1.-Probability predicted by the model of electroshock-induced mortality for Cape Fear shiners exposed to $60-\mathrm{Hz} \mathrm{PDC}$ at various voltage gradients (V/ $\mathrm{cm}$ ) for various exposure periods (s), as a function of fish length $(\mathrm{mm})$. 
predicted probability of mortality ranged from 0.00 to 0.01 for Cape Fear shiners exposed to an electric field of $0.9 \mathrm{~V} / \mathrm{cm}$. The predicted probability for mortality for those receiving 12 -s exposures ranged from 0.00 to 0.16 ; only $63-65 \mathrm{~mm}$ fish were at 0.10 or higher risk for mortality. When voltage gradient was increased to $1.6 \mathrm{~V} / \mathrm{cm}$, the predicted probability of mortality of Cape Fear shiners electroshocked for $6 \mathrm{~s}$ was $0.00-0.22 ; 62$ 65-mm fish had a risk for mortality greater than 0.10 . In contrast, the predicted probability of mortality in Cape Fear shiners electroshocked for $6 \mathrm{~s}$ using $2.3 \mathrm{~V} / \mathrm{cm}$ ranged from 0.00 to 0.67 , where fish greater than $54 \mathrm{~mm}$ risked mortality greater than 0.10 (Figure 1).

\section{Discussion}

We found that the mortality of Cape Fear shiners depended on waveform, voltage gradient, exposure time, and fish length; these results are not entirely consistent with those of other studies of electroshock effects on small fishes. Voltage gradient, pulse frequency, exposure period, and fish length have influenced electroshock-induced mortality of juvenile chinook salmon Oncorhynchus tshawytscha (McMillan 1928; Collins et al. 1954). Mortality increased in fantail darters Etheostoma flabellare and bluegills Lepomis macrochirus with increasing pulse frequency and exposure period (Whaley et al. 1978). On the other hand, neither single nor multiple exposures to DC electrofishing had significant effects on survival of mottled sculpin Cottus bairdi over a 30-d period (Barrett and Grossman 1988). Survival of humpback chub Gila cypha and bonytails G. elegans, endangered cyprinids, was not affected by electroshock though there was evidence of broken blood vessels along the spinal column in some bonytails (Ruppert and Muth 1997). Cooke et al. (1998) found that electrofishing induced little mortality (4-9\%) in greenside darters E. blennoides and noted broken blood vessels and vertebral damage in some fish. The inconsistency in results for electroshock-induced injury and mortality in these various studies, ours included, are probably attributable to differences in species morphology and electroshock exposures; this belief is based on experience but we have no data to support it.

Do the results of our tank experiments have meaningful application to a field setting? Most treatments in our experiments were at or near the threshold for immobilization, a capture-prone response readily recognized in the field. We believe that fish response is the most meaningful basis for comparability of electrical effects between controlled and uncontrolled environments. Fish response depends on the in vivo power achieved in a fish regardless of extraneous factors (see Kolz 1989 for a detailed discussion). For a given level of in vivo power, a fish will exhibit the same response even though its surroundings may vary. Thus, a fish's response indicates that a threshold of electrical field intensity has been reached. The threshold-response relationship is useful for inferences about laboratory results as applied to field operations.

None of the fish in our experiments $(25-82 \mathrm{~mm}$ long), regardless of treatment, were injured (hemorrhage or spinal damage). Despite our use of a high-resolution film-screen system, we failed to achieve the radiographic detail needed to evaluate injury to individual vertebrae. However, hemorrhages and spinal column damage (e.g., compression, separation) would not have escaped detection during necropsy.

Because none of our fish were injured, we must assume that the mortality among the fish in our study was stress-induced (respiratory and osmoregulatory failures were the likely causes; Schreck et al. 1976). We recommend that electrofishers recognize the stress-related aspects of mortality among small fishes by minimizing electrical field intensity to the threshold voltage for immobilization; lower voltages may produce capture-prone responses such as taxis with less stress. Stress is a cumulative phenomenon (Schreck et al. 1976) and must be further minimized by reducing the period of exposure to electroshock. Energizing the electrical field for brief intervals, as opposed to continuous electrofishing (i.e., spot electrofishing; Cooke et al. 1998), is a good way to minimize exposure time; another is to avoid holding fish in a dip net while sweeping in the electrical field for extended periods. Calibrated prepositioned areal shockers (Bain et al. 1985; Larimore and Garrels 1985) may also be used to control exposure period and maximum voltage gradient.

We propose that small cyprinids such as the Cape Fear shiner can be immobilized by electrofishing with $60-\mathrm{Hz}$ PDC with little or no incidence of injury and mortality, provided the electrical intensity remains near the immobilization threshold and exposure periods are kept to $6 \mathrm{~s}$ or less. When establishing sampling protocol, electroshocked fish should be held at least $12 \mathrm{~h}$ to learn if delayed mortality is a possibility. If the cyprinids have protected status, electrofishing need not be immediately eliminated from consideration as a sampling 
tool. Although the potential for harm to individuals in small populations is a vital concern (Mitton and McDonald 1994), our study demonstrates that electrofishing can, in many cases, remain a useful tool for the biologist without jeopardizing fish.

To our knowledge, no previous studies have evaluated voltage gradient, electroshock duration, and fish length for the purpose of predicting electroshock-induced mortality. Although we found that each of these factors was predictive of mortality, the prognostic model that included all three variables $(E, T, L)$ was statistically superior to other models evaluated. We also found that electrical waveform (DC, 60-Hz PDC, $120-\mathrm{Hz}$ PDC) was important for determining survival of electroshocked fish. The $E, T, L$ model is the bestknown information regarding the potential for electroshock-induced mortality of Cape Fear shiners and other small cyprinids of similar physiognomy. The usefulness of the coefficients is probably limited to estimating mortality of Cape Fear shiners and similar small cyprinids. However, biologists should regard electroshock voltage and duration and electrical waveform as risk factors for stress-related mortality in other small fishes.

\section{Acknowledgments}

The staff of the Edenton National Fish Hatchery, U. S. Fish and Wildlife Service (USFWS) provided assistance and suggestions that facilitated our experiments. We are especially grateful to Tom Augspurger (USFWS) and Elliott Atstupenas (USFWS, Edenton National Fish Hatchery) for assistance with permits and fish procurement. Original fish stock was provided by Conservation Fisheries, Inc.; Smith-Root, Inc., of Vancouver, Washington, loaned one of the electrofisher units used in this study. We appreciate the reviews of initial drafts of this manuscript provided by Ronald Barry and Albert Tyler, University of Alaska-Fairbanks. Jeffrey Barrett, Wayne Starnes, and an anonymous reviewer provided helpful criticisms of the work. The U.S. Fish and Wildlife Service and U.S. Geological Survey provided funding for the project. Mention of a commercial product is not intended to imply endorsement.

\section{References}

Bain, M. B., J. T. Finn, and H. E. Booke. 1985. A quantitative method for sampling riverine microhabitats by electrofishing. North American Journal of Fisheries Management 5:489-493.

Barrett, J. C., and G. D. Grossman. 1988. Effects of direct current electrofishing on the mottled sculpin. North American Journal of Fisheries Management 8:112-116.

Buckland, S. T., K. P. Burnham, and N. H. Augustin. 1997. Model selection: an integral part of inference. Biometrics 53:602-618.

Burnham, K. P., and D. R. Anderson. 1998. Model selection and inference: a practical informationtheoretic approach. Springer-Verlag, New York.

Collins, G. B., C. D. Volz, and P. S. Trefethen. 1954. Mortality of salmon fingerlings exposed to pulsating direct current. U.S. Fish and Wildlife Service Fishery Bulletin 56:61-81.

Cooke, S. J., C. M. Bunt, and R. S. McKinley. 1998. Injury and short term mortality of benthic stream fishes-a comparison of collection techniques. Hydrobiologia 379:207-211.

Franklin, A. B., T. M. Shenk, D. R. Anderson, and K. P. Burnham. 2001. Statistical model selection: an alternative to null hypothesis testing. Pages 75-90 in T. M. Shenk and A. B. Franklin, editors. Modeling in natural resource management: development, interpretation and application. Island Press, Washington D.C.

Harrell, F. E., Jr., K. L. Lee, and D. B. Mark. 1996. Multivariable prognostic models: Issues in developing models, evaluating assumptions and adequacy, and measuring and reducing errors. Statistics in Medicine 15:361-387.

Hosmer, D. W., and S. Lemeshow. 2000. Applied logistic regression. Wiley, New York.

Johnston, K. C., A. F. Conners, Jr., D. P. Wagner, W. A. Knaus, X. Q. Wang, and E. C. Haley, Jr. 2000. A predictive risk model for outcomes of ischemic stroke. Stroke 31:448-455.

Kolz, A. L. 1989. A power transfer theory for electrofishing. U.S. Fish and Wildlife Service Fish and Wildlife Technical Report 22:1-11.

Larimore, R. W., and D. D. Garrels. 1985. Assessing habitats used by warmwater stream fishes. Fisheries 10(2):10-16.

Mitton, C. J. A., and D. G. McDonald. 1994. Consequences of pulsed DC electrofishing and air exposure to rainbow trout (Oncorhynchus mykiss). Canadian Journal of Fisheries and Aquatic Sciences 51:1791-1798.

McMillan, F. O. 1928. Electric fish screen. U.S. Bureau of Fisheries Bulletin 44:97-128.

Nielsen, J. L. 1998. Scientific sampling effects: electrofishing California's endangered fish populations. Fisheries 23(12):6-12.

Reynolds, J. B. 1996. Electrofishing. Pages 221-253 in B. R. Murphy and D. W. Willis, editors. Fisheries techniques, 2nd edition. American Fisheries Society, Bethesda, Maryland.

Ruppert, J. B., and R. T. Muth. 1997. Effects of electrofishing fields on captive juveniles of two endangered cyprinids. North American Journal of Fisheries Management 17:314-320. 
SAS. 1999. SAS/STAT user's guide, version 8. SAS Institute, Cary, North Carolina.

Schreck, C. B., R. A. Whaley, M. L. Bass, O. E. Maughan, and M. Solazzi. 1976. Physiological responses of rainbow trout (Salmo gairdneri) to electroshock. Journal of the Fisheries Research Board of Canada 33:76-84.

Snelson, F. F., Jr. 1971. Notropis mekistocholas, a new herbivorous cyprinid fish endemic to the Cape Fear River basin, North Carolina. Copeia 1971:449-462.

Sternin, V. G., I. V. Nikonorov, and Y. K. Bumeister. 1976. Electrical fishing: theory and practice. Translated from Russian original (1972) by E. Vilim. Israel Program for Scientific Translations. Keter Publishing, Jerusalem.

Thompson, K. G., E. P. Bergersen, and R. B. Nehring. 1997. Injuries to brown trout and rainbow trout induced by capture with pulsed direct current. North
American Journal of Fisheries Management 17: $141-153$.

USFWS (U. S. Fish and Wildlife Service). 1988. Cape Fear shiner recovery plan. U.S. Fish and Wildlife Service, Atlanta.

Warren, M. L., Jr., and B. M. Burr. 1994. Status of freshwater fishes of the United States: overview of an imperiled fauna. Fisheries 19(1):6-18.

Warren, M. L., Jr., B. M. Burr, S. J. Walsh, H. L. Bart, Jr., R. C. Cashner, D. A. Etnier, B. J. Freeman, B. R. Kuhajda, R. L. Mayden, H. W. Robison, S. T. Ross, and W. C. Starnes. 2000. Diversity, distribution, and conservation status of the native freshwater fishes of the southern United States. Fisheries 25(10):7-31.

Whaley, R. A., O. E. Maughan, and P. H. Wiley. 1978. Lethality of electroshock to two freshwater fishes. Progressive Fish-Culturist 40:161-163. 